\title{
$\widehat{A}$ Madridge \\ madridge Journal of Nursing \\ interconnecting sic
}

Research Article

Open Access

\section{Smoking Habits and it's Associated Complications among the Omani Population}

\author{
Al-Harthi IS, AL-Shabibi AK, AL-Shabibi ZA, AL-Jabri HM, AL-Khadouri MM, and Hameed Swadi Hassan* \\ School of Pharmacy, College of Pharmacy and Nursing, University of Nizwa, Oman
}

\section{Article Info}

*Corresponding author:
Hameed Swadi Hassan
Associate Professor
School of Pharmacy
College of Pharmacy and Nursing
University of Nizwa
Oman
E-mail: hameed@unizwa.edu.om

Received: July 23, 2018

Accepted: August 8, 2018

Published: August 13, 2018

Citation: Al-Harthi IS, Al-Shabibi AK, AlShabibi ZA, et al. Smoking Habits and its Associated Complications among the Omani Population. Madridge J Nurs. 2018; 3(2): 127-133.

doi: $10.18689 / \mathrm{mjn}-1000123$

Copyright: @ 2018 The Author(s). This work is licensed under a Creative Commons Attribution 4.0 International License, which permits unrestricted use, distribution, and reproduction in any medium, provided the original work is properly cited.

Published by Madridge Publishers

\begin{abstract}
Background: Since smoking is one of the wide spread health risk, and has adverse impact on the health and social aspects and since its habit has not been investigated in Oman, it is chosen to assess this habit and its complications in different regions in Oman.
\end{abstract}

Method: This prospective study was carried out in five different regions in Oman by using a self-administered questionnaire for 1000 Omani smokers during 2012-2016. Questionnaires were designed and included demographic parameters and other parameters chosen from similar previous studies. All the obtained results are illustrated in histograms using excel program.

Results: Out of a total of 1000 known smokers investigated in this study, it was found that the vast majority (97\%) of the participants was males, and the largest percentage (66\%) was in the age range from 20-30 years. The type of smoking experienced is cigarette smoking alone (78\%) and combination of cigarette and shisha smoking (18\%). Shisha smoking alone was encountered only in $4 \%$ of smokers. The reason behind smoking was reported to be due to mood alteration (44\%) and effects of friends (41\%). Less commonly (15\%) smoking was without any apparent reason.

The duration of the smoking reported to be more than ten years in the majority of smokers (51\%). Also, the majority (46\%) of individuals were found to smoke 6-15 cig. / Day and only $6 \%$ found to smoke more than 20 cigarettes daily.

In regards to quitting of smoking, $78 \%$ of smokers reported that they are willing to quit, but about $61 \%$ of people failed to quit and resumed their smoking habit again. The perception of the participants about the best way to quit smoking; is to monitor the children and the teenagers and to increase the participant's and public awareness via media and public education.

Keywords: Smoking habit; Causes of smoking; Cigarettes; Shisha; Oman.

\section{Introduction}

Smoking is a hard habit to break because tobacco contains nicotine, a highly addictive substance that the person needs it just to fell normal [1]. Most people usually start smoking at their teen ages and become addicted at adulthood. Some smokers have tried to quit but failed due to smoking addictive effect. Smoking prevalence is often used as a bench mark for evaluating tobacco activities. In the US, smoking prevalence has decreased by nearly $33 \%-40 \%$. Much of the reduced prevalence has resulted from increased quitting among adults [2]. Studies show that about 9 out of 10 tobacco smokers start before they are 18 years old [3]. Smoking can affect the family because people living together can easily pick up second hand smoke. Second hand smoke may easily lead to lung cancer from inhaling the smoke [4]. 
People start smoking for different reasons such as elimination of stress, social problems, and effects of friends, social acceptance issues, lower educational achievement, and lower economic status [3]. The most common method of smoking today is through cigarettes, but other smoking implements like pipes, cigar, hookahs, vaporizers and bongs are also used.

Tobacco smoking, todays, is the most popular form of smoking and in the meantime, the most commonly used form of recreational drug use. It is practiced by large number of people (over one billion) in the world. Other substances for recreational use include cannabis and opium which are classified as hard narcotics [5], but they are often not commercially available.

Smoking is one of the major burdens on public health, but still inadequate attention has been given to the efforts of the health care professionals who are trying to implement the policy measures to control tobacco use [6]. Tobacco use causes death of about 5.4 million worldwide every year [7] and although overall smoking rate has declined, over years in industrialized or high income countries, smoking rates seem to be higher or increasing in low and middle income countries [8].

Smoking prevalence is highest among young adults (1634 age groups) and continues to be lowest among people aged 60 years and over [9]. Many smokers want to quit but are not sure how to do it [10]. Quitting smoking is so hard, because the tobacco causes psychological and a physical addiction. Quitting smoking may lead to physical withdrawal symptoms [11].

Smokers today tend to smoke fewer cigarettes than in the past [12]. However, smoking fewer cigarettes does not necessarily reduce harms. Quitting smoking is better than reducing the smoking because even those who reduce the smoking significantly experience myocardial infarction and chronic obstructive pulmonary diseases (COPD) close to those of heavily smokers [13]. The risk of a coronary event in exsmokers decline rapidly after quitting and within 2-3 years is similar to the risk for non smoker [14].

Oman is one of the Gulf countries, located at the SouthEast part of the Arabian Peninsula with a total population of 4.8318.106 million out of which only 2.28343.106 are Omanis. The remaining 2.000 .000 million is expatriates [15]. Smoking among males in Oman and in the neighbouring Gulf countries is more predominant compared to that among females. Smoking among females may be seen shameful. In Saudi Arabia for example, the overall smoking rate among King Saud University male students was estimated to be $32.7 \%$ compared to only $5.9 \%$ in females [16].

Cigarettes smoke, natural or otherwise, contains many harmful agents that lead to cancer, cardiovascular and respiratory diseases [17-18]. It is the major cause of diseases in industrialized countries and emerging risk factor in developing countries [19]. In industrialized countries about $40 \%$ of cardiovascular diseases occurring among men and $13 \%$ occurring among women at the age group of 30-69 years have been estimated to be related to smoking [20].
People who stop smoking greatly reduce their risk for diseases and early death, although the health benefits are greater for people who stop at earlier ages [21].

For ischemic heart diseases the excess risk of smoking was estimated to be $100 \%$ for all age groups with active smoking of about $20 \mathrm{cig}$./day. People exposed to passive smoking have a risk of $30 \%$ [22]. These risks are compounded in the presence of hypertension, hypercholesterolemia, glucose intolerance, and diabetes. These diseases exhibit a synergistic effect with smoking. Nicotine and carbon monoxide appear to play major roles in the cardiovascular effects of smoking; quitting smoking results in a dramatic reduction in the risk of mortality from such diseases [23].

Growing evidence from laboratory findings indicate that both active and passive smoking increase cardiac risk through chronic (atherosclerosis) and acute (platelet activation, endothelial dysfunction) pathways. The acute effects are probably transient and may disappear within a short time after cessation of smoking [24].

Female fertility also seems to be affected by smoking [25]. Women who smoke take longer to conceive than women who do not smoke. Women quitting smoking before or early in pregnancy significantly reduce the risk for serious health dangers.

Male fertility reported to be affected too. Male smokers have a lower sperm count and their semen contains a higher proportion of malformed or abnormal sperms. Also, the byproducts of nicotine present in smoker's semen have been found to reduce the motility of sperms [26].

Smoking is difficult to treat, since addiction to tobacco is very strong and withdrawal symptoms may follow cessation of nicotine consumption. The ultimate goal of treatment is smoking cessation. So many public health strategies like antismoking counselling and self-teaching manuals are used in addition to the individual strategies like the use of nicotine chewing gum, clonidine, hypnosis and acupuncture. Still the success rates in smoking treatment are not high and remain between $5-40 \%$ at $1-2$ years. Individualized therapies including care for the smoker as a person, family and labour support are needed to increase the chance of success [27]. However, quitting smoking is hard and may require several attempts. People who quit smoking often start again because of withdrawal symptoms. These symptoms may include stress, weight gain and troubled thinking [28].

In the 1950s, scientists began to report that smoking causes serious health problems including cancer, heart diseases and millions of premature death. Although these findings have become orthodox, their policy implication has been relentlessly challenged; hundreds of millions of cigarettes smokers have defended the right to smoke. By the end of the twentieth century, anti- tobacco advocates, public health officials, physicians, and international organizations, separately or in concert, had succeeded in putting tobacco control on the policy agenda of every industrialized democracy. Cigarette smoking causes more than 480,000 deaths each year in the United States and about $90 \%$ of all 
lung cancer death in man and women. Also, about $80 \%$ of all deaths from COPD are attributed to smoking [29].

Quitting smoking is associated with major health benefits; it lowers the risk for lung cancer and many other forms of cancer, reduces the risk for cardiovascular diseases, reduces the respiratory symptoms; such as coughing, wheezing, and shortness of breath. While these respiratory symptoms may not disappear, they do not continue to progress. Reduces the risk for infertility in women, women who stop smoking during pregnancy also reduce their risk of having a low birth weight baby [30].

The cost of smoking varies greatly depending on the number of packs smoked by the smoker. The average price of a pack of cigarettes in the United States is approximately $\$ 5.5$. This may not seem like that much, until the smoker considers how many of those he consumes in a year. Each year, a person who smokes one pack per day will spend $\$ 2,011$ on cigarettes alone. If a person smokes 2 or 3 packs a day, in a year he will lose $\$ 4,022$ and $\$ 6,033$ on cigarettes, respectively [31].

\section{Need of the study}

Since smoking habit among the Omani people has not been investigated previously and because smoking is widespread in the Sultanate of Oman during the recent years, possibly due to increasing number of expatriates, mostly Arabs, from different countries like Egypt, Syria, Lebanon, Morocco, and Jordon and the possible influence of their cultures on the Omani society, it is chosen to assess this habit and its complications in different regions in Oman. Therefore, the objective of this study is to assess the smoking habit among the Omani population and the possible associated social and health impact on the individuals and the society.

\section{Material and Methods}

The present study is to assess the smoking habit among the Omani individuals with the distribution of questionnaires and to assess the various possible social and health impact associated with this habit. Five regions (Wilayates) were chosen as a sample in Oman. These regions include Muscat (the Capital), AL-Amerrat, Nizwa (AL-Dakhylia), Sur (AlSharqiya), and Al-Suwaiq (Al-Batina). The study was conducted during 2012-2016 by using self-administered questionnaires that included demographic parameters and knowledge about components of smoking, smoking habits and attitudes towards smoking and the possible symptoms and diseases which might be associated with or caused by smoking. The demographic parameters included the individual's age, gender, occupation and education.

A total of 1000 Omani participants (200 in each region) were selected in this study. All participants are well known smokers for several years and all were assured verbally about the confidentiality of their personal data and habits throughout and after the study. Also, all participants were found well educated and all responded to the questionnaires. The questionnaires were based on similar questionnaires used in previous similar studies [32] and modified to match the required information.
These questionnaires were translated in Arabic (the local language) for better interpretation by the selected people and validated. The validity was established by conducting a pilot study. All the obtained data were analyzed by using Microsoft Excel programs and illustrated by histograms.

\section{Results}

The vast majority (97\%) of the people investigated in this study was males, and the largest percentage (66\%) was in the age range from $20-30$ years and about $53 \%$ of them were married and unemployed.

Most of the people investigated (69\%) appeared to be familiar with the components of the smoke. The type of smoking they experienced is cigarette smoking alone in the majority of cases $(78 \%)$ and combination of cigarette and shisha smoking in $18 \%$. Shisha smoking alone was encountered only in $4 \%$ of smokers (Figure.1).

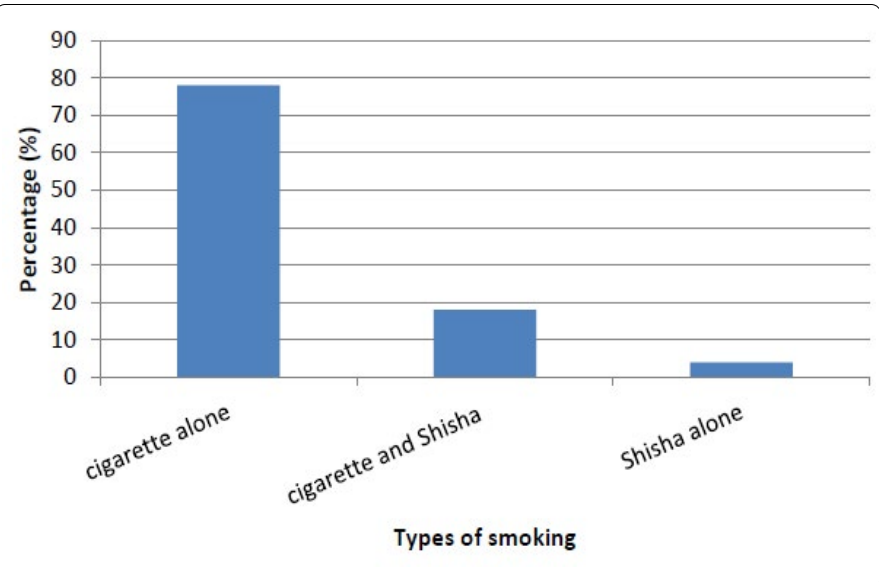

Figure 1. Types of smoking

The reason behind smoking was reported to be due to mood alteration (44\%) and effects of friends (41\%). Less commonly (15\%) smoking reported to be without any apparent reason (Figure.2).

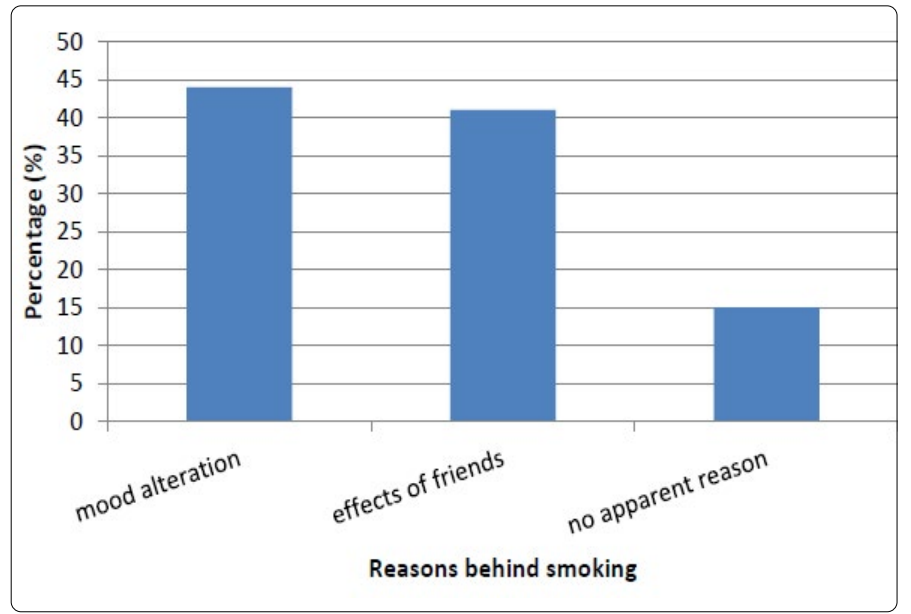

Figure 2. Reasons behind smoking

Smoking the first cigarette was found to be after getting up from bed in the morning in $36.5 \%$ of cases, whereas it was practiced during work in $34.5 \%$ of smokers. However, $29 \%$ of smokers started their first cigarette after breakfast (Figure.3). 


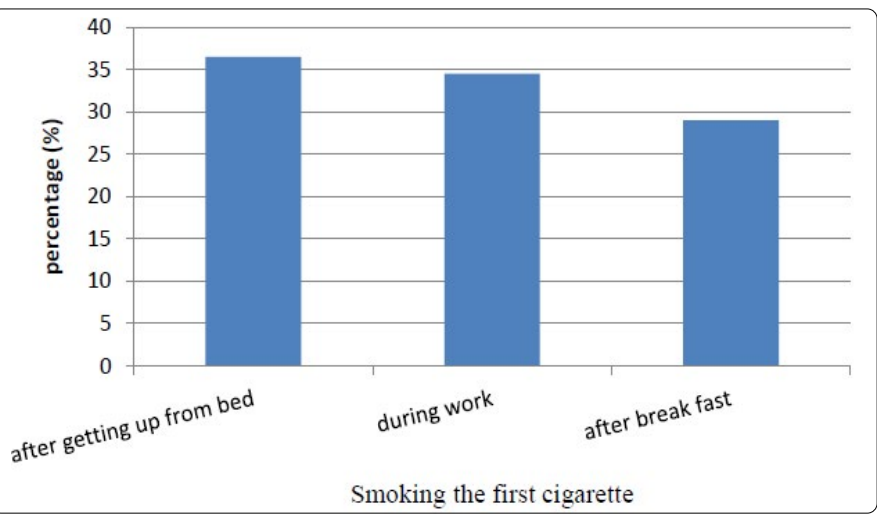

Figure 3. Smoking the first cigarette

The duration of the smoking also reported to be more than ten years in the majority of smokers (51\%), although, this duration seen to be varied among the smokers; some smokers continued to smoke from one to five years $(27 \%)$ or even for ten years (22\%) as appeared in figure.4.

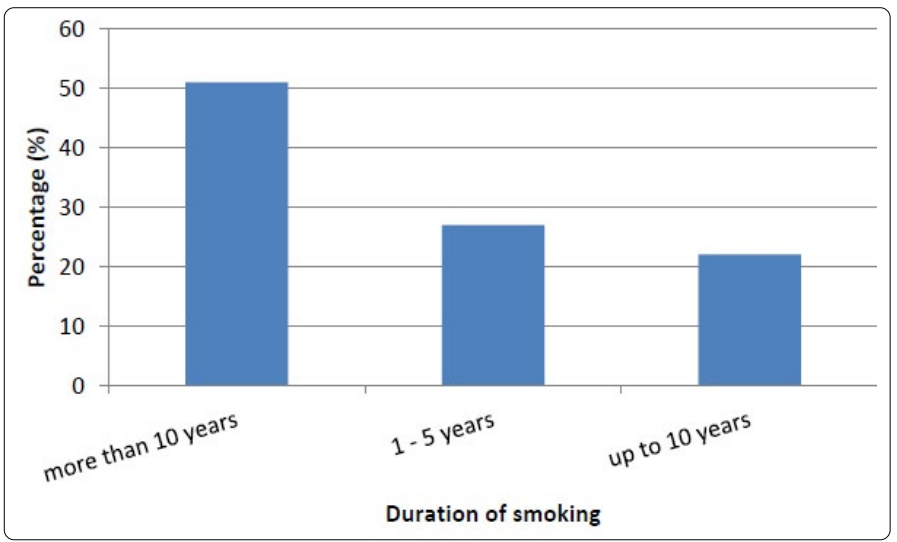

Figure 4. Duration of smoking

About $46 \%$ of participants were found to smoke $6-15$ cig. /day, 32\% smoke about $16-20$ cigarette daily, $16 \%$ found to smoke $1-5$ cig. /day and only $6 \%$ were found to smoke more than 20 cigarettes daily as appeared in figure. 5 .

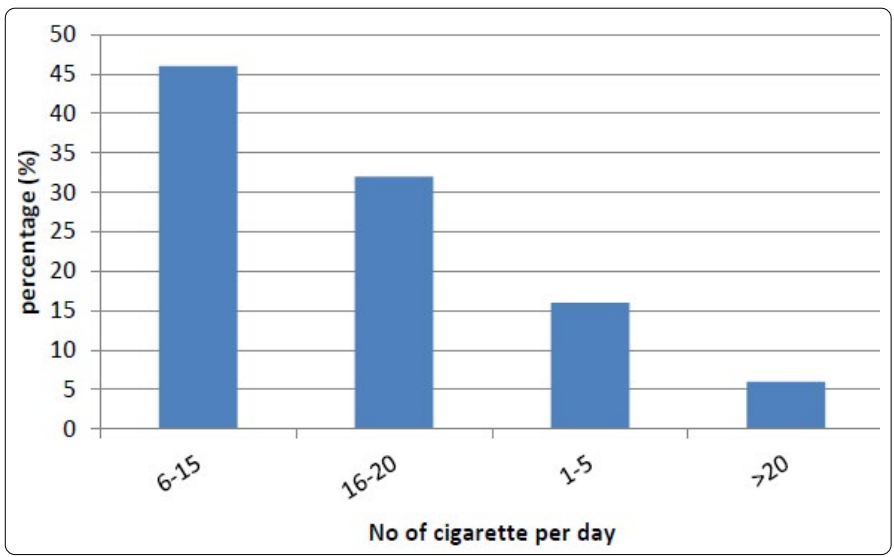

Figure 5. Number of Cigarette

The cost of smoking was found varied among the participants. The majority (42\%) of the participants found to spend $10 \mathrm{RO}(\$ 25) /$ month. Others (32\%) spend 10-20 RO (\$25-50) / month, while the remaining (26\%) spend 20-30 R0 (\$50-75) / month. The latter, high expenditure mainly noticed among smokers in Muscat, the capital of Oman.
Concerning the quitting of smoking, $78 \%$ of smokers reported that they are willing to quit, but about $61 \%$ of those people failed to quit and resumed their smoking habit again. Passive smoking also reported to be known by the majority of participants (73\%). The perception of the participants about the best way to quit smoking is to monitor the children and the teenagers (77\%) and also to increase the individual's awareness via media and public education (23\%). None of the investigated people suggested the use of any known drug (s) for quitting of smoking, but few of them (15\%) noted that visiting specialized centres for advice and counselling might help in quitting of smoking.

In regards to the symptoms or complaints that are associated with the smoking, about $54 \%$ of smokers stated that they are suffering from cough, $26 \%$ suffering from teeth discoloration and bad smell in the mouth while the remaining $20 \%$ reported that they are suffering from loss of appetite. Relative to the associated or pre existing diseases reported by the smokers, it was found that about $37 \%$ have high blood pressure, $32 \%$ of the have high cholesterol level, $21 \%$ have diabetes, and $10 \%$ of the smokers already suffer from bronchitis (Figures. $6 \& 7$ ).

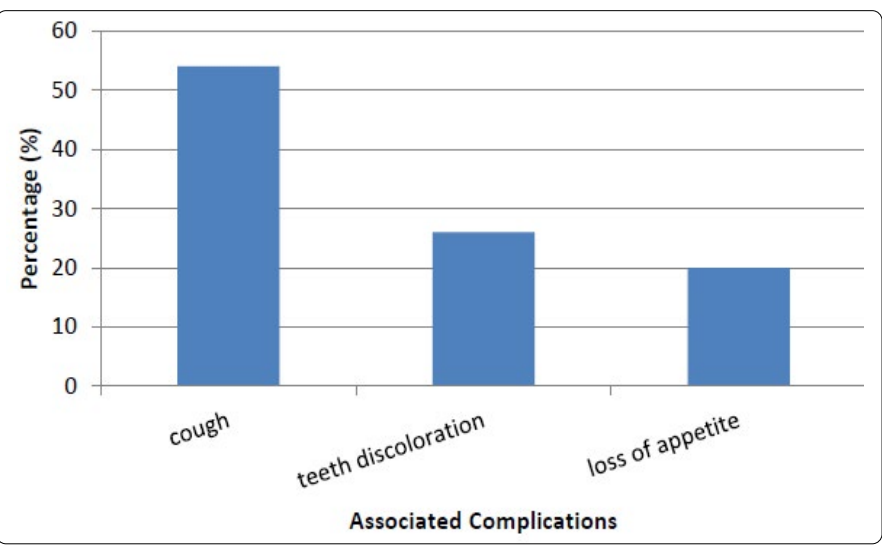

Figure 6. Associated Complications

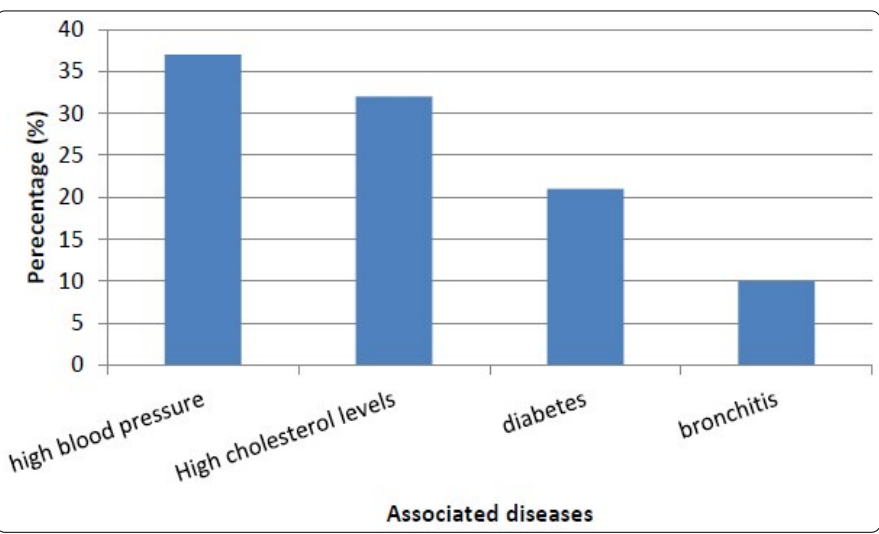

Figure 7. Associated diseases

\section{Discussion}

Comparative data on the prevalence of smoking are not widely available and are often inaccurate, especially when age specific data are required [31]. Smoking prevalence may have been underestimated in most of the studies in Arab countries. 
Males appeared to smoke more than females in Gulf countries. Smoking among females may be seen shameful and for this reason females were very much less encountered in this study (3\%). The overall smoking rate among students of King Saud University (Saudi Arabia) was 32.7\% males compared to only $5.9 \%$ females [16]. In Jordon, the prevalence was $22.4 \%$ for males and 9.1 for female physicians [33]. In Alexandria, Egypt [34], smoking was significantly higher among men than women (48.5\% vs $1.5 \%)$ and the mean age of initiation of smoking was lower in men (18 years) than women (23 years). However, female smoking is more common in the United States and the Western countries [35].

The prevalence of current smoking was studied in Saudi Arabia where it was found to range from $2.4-52.3 \%$ in adults [36]. In the elderly, the prevalence of current smoking was found to represent $25 \%$. Current smoking forms $13-38 \%$ in males compared to $1-16 \%$ in females. In this study $97 \%$ of the current smokers were males and smoking habit appeared to be more among adults (66\%) compared to elderly (17\%). The mean age of initiation of smoking also seen to be higher among young individuals than in other age group; this appeared to be more or less similar to what was reported in Alexandria, Egypt [34]. The duration of smoking was also seen to be long (more than ten years) in $51 \%$ of cases.

Among children and adults (4-17 years) the prevalence of tobacco use is quite low (2\%), but there is a sharp increase up to $25 \%$ in the late adolescence [37]. Among adults population aged 18 years and older, the prevalence of cigarette smoking is high among males rather than females and it is higher in urban rather than rural areas.

Smokers claim to smoke for different reasons. They smoke because they enjoy it (leisure), or because they mimic their friends and family (blind imitation). Others feel it helps them deal with stress, or it is just something they do to pass the time [38]. In Islamabad (Pakistan) causes of smoking were reported as escape of teenagers from the psychological problems or situation like stress [1]. In Saudi Arabia, it has been shown that the common reason for smoking among students of the medical college, KSU, was the influence of friends [18]. The type of smoking reported among students in Saudi Arabia was shisha (44\%), Cigarettes (32.2\%) and both (32.7\%) and the common reason for smoking is the influence of friends. In the present study cigarettes smoking appeared to be the most prevalent type of smoking i.e.78\% and mood alteration and the influence of friends represent the common reasons for smoking.

The hazards associated with long term use of smoking have been shown to be associated with high rate of death (42\%) at age $30-45$ years among British doctors reside in Britain during 1971-1999 [17]. The excess rate of mortality was chiefly from diseases that can be caused by smoking; positive Associations with smoking were confirmed for death from cancers of the mouth, oesophagus, pharynx, larynx, lung, pancreas, and bladder. In England [39], the relative risk of ischemic heart diseases was also seen to be associated with exposure to environmental tobacco smoke where the relative risk was $95 \%$ at the age of 65 years. In Japan, the effect of smoking on sperm motility showed decreased success rates of associated reproduction procedures and adverse effects during fertilization and altered sperms DNA which might affect the development of the embryo [26].

In Sweden, randomized controlled trials were used to encourage smokers to quit smoking by medications and behavioural treatments [27]. Large drop in male daily smoking (from $40 \%$ in 1976 to $15 \%$ in 2002) than female daily smoking (34\% in 1976 to $20 \%$ in 2002) was encountered. Also, during the same time period, lung cancer and myocardial infarction rates have seen to drop significantly among men than women and remain at low levels as compared with other developed countries with a long history of tobacco.

According to work satisfaction, smoking cessation affects the quality of life of smokers. Quitting smoking is related to decreasing ability to cope with stress and has negative effect on life [40]. Large number of smokers does not feel guilty to smoke in front of others because they need to smoke [41].

All smokers trying to quit smoking should receive medication, except when contraindicated or for when insufficient evidence of effectiveness is expected (pregnant women, smokeless tobacco users, light smokers, and adolescents). Appropriate use of tobacco dependence medications reduces withdrawal symptoms and nearly doubles the chances of success for a given quit attempt [41].

Nicotine dependence, like other chronic conditions, offers both challenges and rewards to clinicians. The treatment of this condition frequently requires experience in so many disciplines like pharmacology, behavioural science, and social aspects of medicine. Physicians are, uniquely, qualified to assist patients in their efforts to overcome tobacco addiction. In providing this treatment, the clinical challenges are far outweighed by the benefit to patients who stop smoking [42].

In the present study, $78 \%$ of smokers reported that they are willing to quit, but about $61 \%$ of those people failed to quit and resumed their smoking habit again. The perception of the individuals about the best way to quit smoking is to monitor the children and the teenagers and also to increase the Individual's awareness via media and public education. None of the investigated people suggested the use of any known drug (s) for quitting of smoking, but few people noted that visiting specialized centres for advice and counselling might help in quitting of smoking.

Cough, discoloration of the teeth and bad smell of nicotine and loss of appetite were reported by the people investigated in our study as associated symptoms. Also, many chronic associated diseases like high blood pressure, high cholesterol levels, diabetes and bronchitis as associated or pre existing diseases are also reported. These findings were also reported by so many authors in previous related studies [17-18].

\section{Conclusion}

Based on the obtained results it was found that the vast majorities of smokers is males and in the age range of 20-30 years. The type of smoking experienced is cigarette smoking 
alone and combination of cigarette and shisha smoking. The reason behind smoking was reported to be due to mood alteration and effects of friends. The duration of the smoking found to be of more than ten years in the majority of smokers. In regards to quitting of smoking, $78 \%$ of smokers reported that they are willing to quit but about $61 \%$ of people failed to quit and resumed their smoking habit again. The perception of the individuals about the best way to quit smoking; is to monitor the children and the teenagers and to increase the individual's awareness via media and public education. None of the investigated people suggested the use of any known medication for quitting of smoking.

\section{Recommendations}

This study showed that large number of people is smoking. This need to be taken into great considerations by counselling, media, social education measures to minimize and help quitting smoking to prevent so many associated diseases. Workshops, educational programs might help the community to the hazards of smoking. In addition, more comprehensive and comparable studies are needed in Oman especially after the increase number of expatriates from different Arab countries for better settlement and job opportunities. The influence of the expatriates cultures is very evident in increasing the number of the open cafeterias and prevalent shisha smoking especially in Muscat, the capital, in recent years in Oman.

\section{Acknowledgment}

We would like to express our thanks and gratitude to the University of Nizwa and the College of Pharmacy and Nursing, School of Pharmacy for offering this opportunity to conduct this research via the provision of the academic programs (final year projects). Our thanks are also extended to the respected participants without their kind participation this study cannot be conducted.

\section{References}

1. Khurshid F, Ansari, Urusa. Causes of smoking habit among the teenagers. International Journal of Contemporary Research in Business. 2012; 3(9): 848.

2. Emery S, Gilpin EA, Ake C, Farkas AJ, Pierce JP. Characterizing and identifying" hard-core" smokers: implications for further reducing smoking prevalence. American Journal of Public Health. 2000; 90(3): 87394.

3. Haddad LG, Malak MZ. Smoking habits and attitudes towards smoking among university students in Jordan. International journal of nursing studies. 2002; 39(8): 793-802. doi: 10.1016/S0020-7489(02)00016-0

4. Health risks of Second hand Smoke. https://www.cancer.org/cancer/ cancer-causes/tobacco-and-cancer/secondhand-smoke.html.

5. Ashton $\mathrm{CH}$. Pharmacology and effects of cannabis: a brief review. The British Journal of Psychiatry. 2001; 178(2): 101-106.

6. WHO. Department of Mental Health and Substance Abuse, 2011.

7. WHO Report on the Global Tobacco Epidemic, The MPOWER package, 2008.

8. The World Bank. Curbing the epidemic: governments and the economics of tobacco control. Tobacco Control. 1999; 8(2): 196. doi: 10.1136/ tc.8.2.196
9. General Life style Survey, (2011).

10. Hiller KG, Hawkins JD, Catalano RF, et al. Family influences on the risk of daily smoking initiation. Journal of Adolescent Health. 2005; 37(3): 202210. doi: 10.1016/j.jadohealth.2004.08.014

11. Mahmud A, Feely J. Effect of smoking on arterial stiffness and pulse pressure amplification. Hypertension. 2003; 41(1):183-7

12. Centre for Disease Control and Prevention. National Health and Nutrition Examination Survey 2007-2008.

13. Godtfredsen NS, Vestlo J, Osle M, Prescott E. Risk of hospital admission for COPD following smoking cessation and reduction. A Danish population study. Thorax. 2002; 57(11): 967-972.

14. Dobson AJ, Alexander HM, Heller RF, Lloyd DM. How soon after quitting smoking does risk of heart attack decline? . Journal of clinical epidemiology. 1991; 44(11): 1247-1253.

15. Total population by country 2018. Worldpopulationreview.com/countries/.

16. Mandil A, BinSaeed A, Ahmad S, et al. Smoking among university students: a gender analysis. Journal of infection and public health. 2010; 3(4): 179187. doi: 10.1016/j.jiph.2010.10.003

17. Doll R, Peto R, Wheatley K, Gray R, Sutherland I. Mortality in relation to smoking: 40 years' observations on male British doctors. BMJ. 1994; 309(6959): 901-911.

18. Al-Turki YA. Smoking habits among medical students in Central Saudi Arabia. Saudi Medical Journal. 2006; 27(5): 700-703.

19. Ezzati, $M$, Lopez $A D$, Rodgers $A$, et al. Selected major risk factors and global and regional burden of disease. Lancet. 2002; 360(9343): 13471360. doi: 10.1016/S0140-6736(02)11403-6

20. Ezzati M, Henley SJ, Thun MJ, Lopez A D. Role of smoking in global and regional cardiovascular mortality. Circulation. 2005; 112(4): 489-497. doi: 10.1161/CIRCULATIONAHA.104.521708

21. Treating tobacco use and dependence: 2008 update: Clinical practice guideline. Diane Publishing. 2018.

22. Law MR, Morris J K, Wald NJ. Environmental tobacco smoke exposure and ischaemic heart disease: an evaluation of the evidence. Bmj.1997; 315(7114): 973-980.

23. Arnold CL, Davis TC, Berkel HJ, et al. Smoking status, reading level, and knowledge of tobacco effects among low-income pregnant women. Preventive medicine. 2001; 32(4): 313-320. doi: 10.1006/pmed.2000.0815

24. Raupach T, Schäfer K, Konstantinides S. Andreas S. Second hand smoke as an acute threat for the cardiovascular system: a change in paradigm. European Heart Journal. 2006; 27(4): 386-392. doi: 10.1093/eurheartj/ ehi601

25. Hull MG, North K, Taylor H, Farrow A, Ford WC. Delayed conception and active and passive smoking. Fertility and sterility. 2000; 74(4): 725-733.

26. Sofikitis $\mathrm{N}$, Takenaka $\mathrm{M}$, Kanakas $\mathrm{N}$ et al. Effects of cotinine on sperm motility, membrane function, and fertilizing capacity in vitro. Urological research. 200; 28(6): 370-375.

27. Bello S. Treatment of smoking. Revistamedica de Chile. 1991; 119(6): $701-$ 708.

28. Cerdá M, Wall M, Keyes K M, Galea S, Hasin D. Medical marijuana laws in 50 states: investigating the relationship between state legalization of medical marijuana and marijuana use, abuse and dependence. Drug and alcohol dependence. 2012: 120(1): 22-27. doi: 10.1016/j.drugalcdep.2011.06.011

29. US Department of Health and Human Services, 2014. The health consequences of smoking-50 years of progress: a report of the Surgeon General. Atlanta, GA: US Department of Health and Human Services, Canters for Disease Control and Prevention, National Canter for Chronic Disease Prevention and Health Promotion, Office on Smoking and Health, 17.

30. Jha P. Avoidable deaths from smoking: a global perspective. Public Health Reviews.2011; 33(2), 33(2): 569-600.

31. Townsend J, Roderick P, Cooper J. Cigarette smoking by socioeconomic group, sex, and age: effects of price, income, and health publicity. Bmj. 1994; 309(6959): 923-927. doi: 10.1136/bmj.309.6959.923 
32. Davies GM, Willner $P$, Morgan M. Smoking-related cues elicit craving in tobacco" chippers": a replication and validation of the two-factor structure of the Questionnaire of Smoking Urges. Psychopharmacology. 2011; 152(3): 334-342.

33. Wald NJ, Hackshaw AK. Cigarette smoking: an epidemiological overview. British medical bulletin. 1996; 52(1): 3-11.

34. Bedwani R, El-Khwsky F, La VC, Boffetta P, Levi F. Descriptive epidemiology of bladder cancer in Egypt. International journal of cancer. 1993; 55(2): 351-352. doi: 10.1002/ijc.2910550228

35. Fiore MC, Novotny TE, Pierce JP, et al. Trends in cigarette smoking in the United States: the changing influence of gender and race. Jama. 1989; 261(1): 49-55. doi: 10.1001/jama.1989.03420010059033

36. World Health Organization, 2005. Smoking statistics, fact sheet 2002. WHO, Regional Office for the Western Pacific.

37. Peto R, Lopez AD. The future worldwide health effects of current smoking patterns. Tobacco and public health: Science and policy. 2004; 281(6): 154161.
38. Harding R, Maritz G. Maternal and fetal origins of lung disease in adulthood. Seminars in Fetal and Neonatal Medicine. 2012; 17(2): 67-72. doi: 10.1016/j.siny.2012.01.005

39. Tsutsumi A, Kayaba K, Yoshimura M, Sawada M. Association between job characteristics and health behaviors in Japanese rural workers. International Journal of Behavioral Medicine. 2003; 10(2): 125-142.

40. Piper ME, Kenford S, Fiore MC, Baker TB. Smoking cessation and quality of life: changes in life satisfaction over 3 years following a quit attempt. Annals of Behavioral Medicine. 2013; 43(2): 262-270.

41. Tobacco T.C.P.G.T. A clinical practice guideline for treating tobacco use and dependence: 2008 update: a US public health service report. American journal of preventive medicine. 2008; 35(2): 158-76. doi: 10.1016/j. amepre.2008.04.009

42. Epps RP, Manley MW. The clinician's role in preventing smoking initiation. Medical clinics of North America. 1992; 76(2): 439-449. doi: 10.1016/ S0025-7125(16)30361-3 